\title{
Non-Realism and Ontology in Gus Van Sant's Paranoid Park
}

\author{
By Alessandro Zir \\ Spring 2010 Issue of KINEMA \\ BEYOND SUBJECTIVENESS: NON-REALISM AND ONTOLOGY IN GUS VAN SANT'S \\ PARANOID PARK
}

\begin{abstract}
This paper focuses on Gus Van Sant's Paranoid Park (2007), in order to raise ontological issues that are understood to be fundamental to quite idiosyncratic, "authorial" movies, which are frequently mischaracterized as being merely personal and subjective. It starts with a consideration of how ontology must have a primacy over what is merely subjective or psychological in aesthetic experience. Paranoid Park is then analyzed in detail, with special attention to the apparently random elements that pullulate both in its soundtrack and in its visual texture. It is defended that the material with which the movie is made is emancipated from what would be their mere functionality in respect to the story. The same is true about a vagueness that is conspicuous to its characters. The violent scene of the railway accident, the dramatic apex of the movie, acquires a peculiar significance in view of these considerations.
\end{abstract}

THERE IS something quite idiosyncratic, and difficult to define, which is common to movies such as Gus Van Sant's Elephant (2003), Last Days (2005) and Paranoid Park (2007). Along with Béla Tarr, Andrei Tarkovsky has been acknowledged by Gus Van Sant as one of his main influences (Peary, 2003). Tarkovsky was surely a film director whose movies stand out because of their radical singularity. Indeed, Tarkovsky seems to have believed that cinema as art was essentially subjective. The most subjective of all arts, as he wrote in his notebooks: "cinema is the most personal art, the most intimate. In cinema only the author's intimate truth will be convincing enough for the audience to accept" (Tarkovsky, 1994: 101). But Tarkovsky also recognized his desire to go beyond what is subjective and personal. He asked himself: "Is it possible to go beyond human consciousness and make a new, non-subjective assessment of reality?" And he answered positively: "It is not considered to be possible, but I somehow feel it may be" (Tarkovsky, 1994: 316). This essay focuses in Gus Van Sant's Paranoid Park, and defends that what is most singular and idiosyncratic in such an almost hermetic movie is not simply subjective or personal. It is certainly not an expression of anything that could be labelled psychological. Critics have missed completely the target when they try to make sense of Gus Van Sant in terms of a flirt with the "dark side" of society and its outcasts, or an obsession with "young males" (Gritten, 2007). What happens in Paranoid Park is the unravelling of something objective. It has much more to do with ontology than with psychological or even sociological categories.

In the philosophical tradition as well, metaphysical, ontological issues were frequently misunderstood as merely psychological and subjective. In order to avoid such mistakes, in his book about Henry Bergson, Gilles Deleuze emphasized that the importance Bergson gives to intuition has to do with ontological concerns. Intuition is what enables one to affirm and to recognize the existence of others, other persons and also other things. It is as well what enables one to go beyond dichotomies such as between idealism and realism (Deleuze, 1966: 25). The Bergsonian concept of durée has to do rather with a variable essence of things in a complex ontology than with psychological experience. It is not merely subjective (Deleuze, 1966: 27). The ontological weight of these Bergsonian notions was equally underlined by at least one author who incorporated them in a straightforward aesthetic theory. This was the case of Theodor Adorno, who not only was greatly influenced by Bergson (and Marcel Proust) (Menke, 1998: 31; cf. Adorno, 1997: 132), but paid the most careful attention to the objective dimension of art. Aesthetic experience, for Adorno, negates automatic understanding, that is, the reification of cognitive categories that do nothing but mechanically reproduce socially acquired habits (Menke, 1998: 31). The negation fomented by aesthetic experience, however, is not genuinely attained by merely ignoring conceptual knowledge. It has to be grounded in the concrete interactive processes that generated it (Menke, 1998: 65, 236). For Adorno, art has something objective, as is exemplified, for instance, in issues related to musical interpretation and enactment (Adorno, 1997: 125; $c f$. 132). 
Gus Van Sant's Paranoid Park gives a lesson in this sense. It is very idiosyncratic, non-realistic. It defies the way people usually organize things in space and time. But by doing this, it points to what, beyond the psychological, is objective. It accesses reality in a non-subjective way, as other cineastes such as Tarkovsky aspired to do. It has been said (correctly) that Paranoid Park displays "a contentment with cinematic 'nowness' (as opposed to a build-up to 'what comes next')". In terms of its sound, this led Gus Van Sant to pay attention to "the sound of a place and moment which envelops and opens itself to the characters in their stillness or continuous movement" (Kulezik-Wilson, 2008: 128). Gus Van Sant was able to recognize "the musical potential in the rhythmic, kinetic and affective features of a number of film's constituent element structuring, editing, camera movement, movement in the diegesis, speech, etc." (Kulezik-Wilson, 2008: 127). This is a concern with the very singularity of the material with which the film is made, which is not treated only instrumentally (as a mean to convey the story), but has an inner value. ${ }^{(1)}$ The material is emancipated. It is as much important as the characters themselves, and as much as them, it is not simply subsumed to the narrative understood as a disembodied story.

In the opening take of Paranoid Park one encounters a natural element common to other of Gus Van Sant's movies, at least since My Private Idaho (1991): the movement of clouds. This is an objective element that crosses those movies, and by itself it constitutes a reference (be it conscious or not), with the music (certainly conscious), to other cinematic experiences, such as Federico Fellini's mysterious classics: Toby Dammit (1968) and Giulietta degli spiriti (1965). In Paranoid Park, the mesmeric and slow movement of heavy clouds in the sky makes a huge contrast to the accelerated cars running in the opposite direction over St. Johns' bridge in Portland - a city of many bridges. A similar contrast is repeated in the music of the soundtrack, which in a moment is animated and accelerates just to fall back suddenly to its original suspended, restrained movement. Besides this contrast in the music, there is already here another quite specific audible element: the sound of the wind hitting the camera, intertwined with the music, but in its own, independent, rhythm. The harshness of this noise, which might be taken as something extravagant, the unsuppressed casual product of the environment where the camera had to be placed, almost imperceptibly connects with the title of the movie. The latter is written down in a washed out pencil lead over a slanted and moving scrapbook paper. The title is oppressed under the hand that registers it, being actually announced by its sound. It is the harshness of the process of scratching that itself singles out, quite a part from the meaning of the words. This harshness, already present in the movement of the wind hitting the camera, unfolds itself in several, entangled, complex grates that punctuate the soundtrack of the whole movie. These audible harsh elements double into visual ones during the record of the skating: the texture of the image in these takes is rough and granulated. There are other elements of visual noise here: the reflected light invading the camera, its instability, the abrupt angles and unusual framing, the slow down of the movement. In terms of sound, in these passages of skating, there are birds and French lyrics (which is quite unexpected in an English speaking movie). It is now as if one has entered in an intensive dimension in which the attrition that is typical of the rolling of the skate's wheels over the concrete was decelerated and expanded in a myriad of elements seen in constellation.

Another kind of attrition keener and almost literally painful is the one produced by suddenly breaking the wheels of a train over the rail. Such a sound can be easily associated to what is the dramatic apex of the narrative (the running over of the security guard in the railway). The scene of the accident starts to emerge only in the second half of the movie, but in its extreme violence it is anticipated in a series of radical cuts and contrasts, already when Alex (the main character) drives the car of his mother towards Paranoid Park. Occurring in several levels, all at the same time, the ruptures in these driving passages are total ones. There are blocks mowed down one from another. The soundtrack changes from a relaxed rap to an intense passage of a Beethoven's symphony, and then to the noise of the opening of the electric pan of the car and the voice of the waitress in the microphone of the drive in. The facial expression and movements of Alex also radically change in each one of these blocks. And the several random elements that interfere with the caption of the images, which is done always from behind the windshield, rise up with different relevance: what gains prominence are now the lights of the cars behind, now the mist, now the drops of the rain, now the wiper, now the shadow of the of car's roof over the face of the character.

The characters appear frequently hooded, filmed from behind, walking away from the camera. When they appear facing the camera, many times their face is partially covered by hair, or they are self-absorbed, 
looking down. There are many scenes in which only feet or legs walking are shown. Not only parts of the body, but physical fragility, the somatic dimension of the body, is accentuated, by a permanent sensation of exposition to wetness and cold: bare feet, wet hair, the eyes contracted and blinking (as in the scene in the beach, when Alex stands up and walks against the wind, after the title of the movie appears written for the second time). There are also vomits. This point was actually stronger in Gus Van Sant's previous movie, The Last Days. One should note, however, that it is not the case that the characters were not able to interact in an effective way. That they are capable of doing so is shown, for instance, in the passages in which the police detective interrogates Alex and later the community of skaters in the school. It is, however, as if they were not so much interested to interact in that way.

Alex has even a critical awareness that he tells his story out of order, that he has trouble in organizing it: "I'm writing this a little out of order. Sorry. I didn't do it so well in creative writing. But I will get everything on paper, eventually". But to whom would his writing be addressed? When he is first questioned what he is writing, his answer is quite evasive: "What are you writing? Oh, nothing, just homework. What are they for?" To his own father, apparently the person to whom he should confess, he gives up telling anything. In the end, the story is simply burned. All relations are kept uncertain. In the case of his parents, he says "my dad had supposedly moved out, but he keeps calling the house". His feeling about his girlfriend is "I just wish I liked her more, that we have more in common". Alex and Jennifer (his girlfriend) appears as quarrelling, then as having fun together. The relation with his best friend is also mysterious. There is a scene in which Alex's new skateboard is called a "fag skate", then they make eye contact. The look of his friend is extremely sexy, if ironic, and intensified by the heavy and vibrant sound of a bass. But the movie does not infer any lesson from any of these uncertainties, it is not moralist.

In the hands of another director, it would be easy to fall in clichés of social criticism. But Gus Van Sant is in no way demagogical. He does not present any easy solution to the material he is dealing with. What gains emphasis are the elements themselves, the intensive deceleration and expansion of intervals, distilled from the context, as in the scene in which Alex make eye contact with the stranger in the park, or in the scene in which, after the accident, his head appears covered by hair, by his hands, under the shower. From his dialogue with the most articulate person in the movie, his friend Macy, it is possible to infer the following: "little", particular "problems", if "they are happening to you", are as important as big, social ones, such as "people dying in Iraq". And the global issues of the Iraq war are boldly belittled even more straightforwardly in the second dialogue between Alex and Macy, which ends with a "whatever..." Paranoid Park sticks to the most immediate, contiguous reality of the characters, which touches again on ontological issues. Alex feels "that there is something", "outside normal life", "right there". What he feels is not, however, a mere object in ordinary reality, the Iraq war, the railway accident. He is talking about focusing on "different levels of stuff", as if he were longing to diffract, decelerate and intensify in the same way as does the movie itself. It is only in this perspective that he can acknowledge the accident, and finally confess to Macy: "there is something that happened to me". The upper half of a human body crawling towards him, at the same time alive, looking, and losing its guts. By its literal realism, this image is unreal, as in the case of the violence depicted in the movies of Tarantino or Robert Rodriguez (for instance, Grindhouse, released in the same year). It is unreal not in the sense of being merely psychological, subjective, a delusion. Much on the contrary, it is unreal in the sense of radically challenging experience as it is socially or psychologically organized in ordinary situations.

\section{Notes}

1. I use material here in the very broad sense that was used by Adorno: "Material is what artists work with: it is the sum of all that is available to them, including words, colors, sounds, associations of every sort and every technique ever developed. To this extent, forms too can become material; it is everything that artists encounter about which they must make a decision" (Adorno, 1997: 148). 


\section{References}

\section{References}

Adorno, Theodor W. Aesthetic Theory. Minneapolis: Univ. of Minnesota Press, 1997.

Deleuze, Gilles. Le Bergsonisme, Paris: Presses Universitaires de France, 1966.

Fellini, Federico. Toby Dammit (1968) .

Fellini, Federico. Giulietta degli Spiriti (1965).

Gritten, David. "Paranoid Park: The Voice of Doomed Youth". Thelegraph.co.uk, December 2007:

http://www.telegraph.co.uk/culture/film/3670186/Paranoid-Park-The-voice-of-doomed-youth.html

Kulezik-Wilson, Danijela. "Sound Design is the New Score." MSMI 2 : 2, Autumn 2008.

Menke, Christoph. The Sovereignty of Art: Aesthetic Negativity in Adorno and Derrida. Cambridge, Mass.: MIT Press, 1998.

Peary, Gerald. "Gus Van Sant - Elephant". Boston Phoenix, November 2003:

http://www.geraldpeary.com/interviews/stuv/van-sant-elephant.html

Rodriguez, Robert \& Tarantino, Quentin. Grindhouse (2007).

Tarkovsky, Andrei. Time within Time. The Diaries. 1970-1986. London: Faber and Faber, 1994.

Gus Van Sant, My Private Idaho (1991)

Gus Van Sant, Elephant (2003)

Gus Van Sant, Last Days (2005)

Gus Van Sant, Paranoid Park (2007)

\section{Author Information}

Alessandro ZIR, (PhD Dalhousie, Halifax) is a journalist and philosopher, with publications in Brazil, Chile and Portugal, including chapters of books, papers, translations, and fiction. He is a member of the GIFHC (Interdisciplinary Ground in Philosophy and History of Science), ILEA/ UFRGS - Brazil. 